\title{
Internet Addiction Among Medical and Non-Medical Students During COVID-19 Pandemic, Tanta University, Egypt
}

Walaa M. Shehata

Tanta University

Doaa E. Abdeldaim ( $\nabla$ doaam3y@gmail.com )

Tanta University

\section{Research Article}

Keywords: Internet, Addiction, Students, COVID-19, Tanta, Egypt

Posted Date: May 4th, 2021

DOl: https://doi.org/10.21203/rs.3.rs-420615/v1

License: (c) (i) This work is licensed under a Creative Commons Attribution 4.0 International License.

Read Full License 


\section{Abstract}

Background: Internet addiction is one of the most growing addictive behaviors worldwide, especially among university students affecting their physical and mental health negatively. It increased significantly during period of unusual events of COVOD-19 pandemic.

Aim: To assess the level of internet addiction among medical and non-medical students in Tanta University, Egypt.

Methods: This was a cross-sectional study conducted during October and November 2020. It included 373 students from faculty of medicine and 373 non-medical students from faculty of science. The validated (IAT-20) was used to assess the level of internet addiction among these students.

Results: $51.7 \%$ of medical students were found severe internet addicts and $43.4 \%$ of them were possible addicts compared to only $11.3 \%$ of non- medical students were severely addicted to internet and $68.9 \%$ of them were possible addicts with statistically significant difference between them. Female students of both colleges were found addicted to internet than males.

Conclusions: Medical students and female medical and non-medical students suffered from severe internet addiction more than non-medical and male ones.

Recommendations: Appropriate awareness creation intervention strategies should be implemented to decrease the level of internet addiction among university students and to reduce its harmful and negative consequences.

\section{Introduction}

Since COVID-19 pandemic started and significant measures were taken worldwide to reduce the spread of the virus in the form of lockdowns of educational institutions and social avenues and keeping social distancing among people (Fernandes et al. 2020).

These measures led to major changes in daily routine and activities of adolescents and adults and this in turn affected their psychological well-being (Fegert et al. 2020). Studies done in China (Wuhan), the first place of COVID-19 virus, showed that people experienced the consequences of lockdown measures, like living a sedentary life and get involved in problematic use of internet as a way of escapism from these stressful events (Király et al. 2020).

Although proper use of internet is useful, but also its problematic use is usually resulting in undesirable consequences and even lead to a state of addiction. In general, addiction is a "compulsive need for and use of a habit-forming substance", this state is characterized by tolerance and occurrence of physiological symptoms on withdrawal (Merriam-Webster's Dictionary, 2019). Internet addiction (IA) is defined as "a kind of technology addiction and a behavioral addiction similar to a gambling habit" (Griffiths 2000). 
This addiction is considered as a psychological dependence on the use of internet which is characterized by excessive use, tolerance, craving, mood changes and withdrawal symptoms on quitting (Mercy and Oluwatosin 2015 and WHO 2015).

Statistics reported that the number of active internet users, increased from 2.5 billion in 2014 to 3.7 billion users in 2017 , especially among adolescents and young persons. Moreover, it was reported that $56.7 \%$ of the population in the Middle East were active internet users which was about $3.8 \%$ of the active internet users all over the world (Ali et al. 2017).

In October 2020, it was found that 4.66 billion persons were active internet users, which forms about $59 \%$ of the total world population. $91 \%$ of those users accessed the internet through mobiles as mobiles became the most important and the most common channel to get an access to internet (Johnson 2021).

The highest number of internet online users was found in Asia with more than 2.3 billion, and Europe was the second with about 728 million internet users. UAE, Denmark, and South Korea were the highest countries in the internet access rate, while China, India and the United States were found the highest regarding the numbers of internet users with approximately 854 million online users were found in China, and more than 560 million internet users in India (Johnson 2021).

In Egypt, the rate of internet penetration was $54 \%$ with about 54.74 million internet users were reported in January 2020, it was found that this number was increased by about 22\% (9.8 million) from 2019 to 2020. Moreover, the number of social media users in Egypt also increased by about 7.3\% from 2019 to 2020 to reach approximately 42.00 million users (KEMP 2020).

However, The prevalence of problematic internet use among college students has not been established, studies in USA reported that $5-12 \%$ of university students in different colleges suffered from internet addiction (Derbyshire et al. 2013). In Asia, the prevalence was 3.7\% in India (Patil et al. 2017) and increased to $37 \%$ in Iraq and Malaysia (Babakr et al. 2019). In African countries, the range of prevalence was found from 5.1\% in Mauritius (Smita et al. 2018) and reach to 16.8\% in Kenya (Maroma et al. 2019).

As internet addiction increases among university students especially after the occurrence of COVID-19 pandemic, its negative physical, mental and social consequences increase and affect their life and psychological wellbeing very badly (WHO 2015 and Lee et al. 2019). These consequences may include lack of sleep, bad eating habits, psychological distress, depression, anxiety, aggression, getting involved in other forms of addiction as smoking or alcohol use and it may even reach to suicidal attempts. Also, problematic use of internet may lead to cognitive impairment and poor academic achievements (Salubi et al. 2018). Moreover, internet addiction can lead to physical problems such as ophthalmic, hearing, musculoskeletal problems and even thromboembolism (Lee et al. 2019).

Aim of this study was to assess the level of internet addiction among medical or non-medical students in Tanta University, Egypt. 


\section{Participants And Methods}

Study design: A cross-sectional study

\section{Study population and sampling:}

The study was conducted during October and November 2020 at the faculties of Medicine and Science, Tanta University, Egypt. Faculty of science was selected as an example of non-medical faculties in Tanta University. The students' numbers were enumerated then the questionnaire was randomly distributed to the participants. Participants were selected through disproportionate probability stratified sampling technique. Study criteria included; (a) fourth year students from both faculties, (b) students were willing to participate.

\section{Sample size and sampling technique:}

Prevalence of IA is $47 \%$ according to the results of a previous study conducted in Sohag governorate among medical students in Sohag University (Ali et al. 2017) and with a precision of $5 \%$ and $95 \%$ confidence interval, a minimum sample size estimated was 380 subjects. The total sample size was 746; 373 students from faculty of medicine and 373 non-medical students from faculty of science. All the students were from fourth year. Sample size calculated by using EPi Info. Objectives of the study were explained to the students. Response rate was $98 \%$. This was a valid and reliable questionnaire (Cronbach's Alpha 0.88).

\section{Study tool:}

A self administered structured questionnaire consisted of two parts used in this study. The first part included items on sociodemographic factors (age, gender, marital status, education, residence and family income). The second part was internet addiction test (IAT) originally developed by Dr. Kimberly Young(Young 1998). The IAT questionnaire has also been validated in various countries and has been used in some studies (Bahrainian et al. 2014, Krishnamurthy and Chetlapalli 2015). The IAT questionnaire is used as screening tool to examine the level of internet addiction. The questionnaire consisted of 20 items to examine symptoms of IA based on a 5-point Likert scale ranging from ( $0=$ not applicable, $1=$ rarely, $2=$ occasionally, $3=$ frequently, $4=$ often, $5=$ always). At last the scores of all questions had been summed up and level of internet addiction was evaluated based on the final score. The severity of IA according to the IAT was as follows: $20-49$ points is 'average internet users'; $50-79$ points is 'possible problematic internet users'; and 80-100 points is 'severe internet addict with internet usage causes significant problems in users life'.

\section{Ethical considerations:}

Approval from the ethical committee of Faculty of Medicine, Tanta University was obtained before conduction of the study. Objectives of the study were explained to all the included students. 
Confidentiality of collected data was confirmed to all participants. Informed oral consents were obtained from those willing to participate before continuing the study.

\section{Statistical Analysis:}

Statistical Package for Social Sciences (SPSS) (version 16.0, IBM, Armonk, NY) was used to analyze data of the study. Descriptive presentations were done for all variables of the study and comparison between groups was done by using chi square test. Level of significance was at $p<0.05$.

\section{Results}

A total 746 students completed the questionnaire. 373 non-medical students were from the faculty of science (group I) and the same number was taken from the faculty of medicine (group II). Table (1) showed the sociodemographic data of the studied students. Most of respondents were females $(64.3 \%$ and $70 \%$ in group I and II respectively) and more than half of them from urban areas. $92 \%$ and $94.6 \%$ of both groups were not married. According to family income, more than half of them in both groups (53.4\% and $54.4 \%$ respectively) had just enough income. According to Table (2); most students reported often/always staying online longer than intended, neglecting their house chores and preferring excitement of internet than intimacy with their partner. Most respondents in both groups stated often/always their academic grades and their productivity were affected. $41.6 \%$ of non-medical students reported that at least occasionally become defensive or secretive when anyone asked about their online presence while $53.4 \%$ of medical students reported at least often defensive. They lost sleep at night due to internet use in $44 \%$ and $64.1 \%$ in non-medical and medical students respectively. More than four fifths in both groups felt depressed or moody when they were offline. Table (3) illustrated that medical students were severely addicted to internet more than non-medical students with statistically significant difference between them with $68.9 \%$ of non-medical students were possible addicts to internet while $51.7 \%$ of medical students were severely addicted to internet. Table (4) showed the relation between the level internet addiction and sociodemographic data of the studied groups. There was no significant difference between the level internet addiction and gender, residence, marital status and family income.

\section{Discussion}

Internet addiction or Problematic internet use became a growing social and public health problem, affecting people worldwide (WHO 2015), especially teenagers and university students (Kuss and LopezFernandez 2016) leading to many negative consequences (Lee et al. 2019).

The present study showed that the majority of medical students $(76.4 \%)$ reported at least often staying online longer than intended. This is quite similar to results reported by Taha et al., 2019 in their study in Qassim University, Saudi Arabia as $70.8 \%$ of their medical students reported that staying at least often online longer than intended (Taha et al. 2019). Both studies reported much higher findings than those 
found by Haque et al., in their study on medical students in a Malaysian medical school as they found only $30.9 \%$ of students at least often staying online longer than intended (Haque et al. 2016).

More than $75 \%$ of medical students in the current study neglected their household chores to spend more time online at least frequently. This is more than Taha et al. findings from their study in Saudi Arabia (52.7\%) (Taha et al. 2019) but these findings are much higher than those of a study done among Malaysian medical students with only $12.7 \%$ of students at least often neglected their household chores (Haque et al. 2016) and also more than another study done in Japan (Sato 2006).

The findings of current study on students' preferences to use internet over interaction with partners, colleagues and friends were higher than findings of another studies conducted in Malaysia, Egypt, Kuwait and India (Al-Menayes 2015, Saied et al. 2016and Patil et al. 2017).

The majority of medical students in the present study received complaints from others because of spending long time using internet which is much higher than what was found by Haque et al. and Taha et al. as they found only one quarter of their medical students got complaints (Haque et al. 2016and Taha et al. 2019).

The current study reported that $59.8 \%$ of medical students stated at least often their academic grades and their productivity were affected and $53.4 \%$ of them reported at least often become defensive when anyone asks you what you do online. Our results are higher than those of Taha et al., 2019 study (31.6\% of medical students reported that internet use at least often affected their academic performance and $33.4 \%$ of them at least often became defensive) (Taha et al. 2019). However, Haque et al., found much lower negative affection of academic performance of their medical students as only $12.1 \%$ of students reported that their academic performance was at least often affected by internet use (Haque et al. 2016).

Regarding sleep, $64.1 \%$ of the medical students in the current study at least often lost night sleep because of late use of internet which is higher than those found by Taha et al. in their study (42.6\%) (Taha et al. 2019), while only 12.8\% was found by Haque et al. 2016.

Moreover, the majority of our medical students (86.6\%) were found at least often depressed or moody when they were offline. This is higher than that found by Taha et al., 2019 as $60.7 \%$ of their included medical students felt at least frequently depressed when they are offline (Taha et al. 2019). These results were in line with findings from other studies done in Korea and India (Whang et al. 2003and Srijampana et al. 2014).

In contrary only $9.4 \%$ of students in the Malaysian study were found at least often depressed or moody when they were offline (Haque et al. 2016).

Regarding the non-medical students, the present study found that $61.1 \%$ of them stay online longer than intended at least often, which was less than that found by Salubi et al. in their study in South African universities, as they found $71.3 \%$ of undergraduate students stay, at least often, on internet longer than intended (Salubi et al. 2018). 
In contrary to our findings, Salubi et al. found that only $32.3 \%$ of South African college students enjoyed excitement of using internet more than spending time with their friends which was much lower than our findings (64.1\%) (Salubi et al. 2018).

Dissimilar to our results as we found only $44 \%$ of non-medical students often/always lost sleep on using internet late, Salubi et al., found that $71 \%$ of their college students often/always lost sleep (Salubi et al. 2018).

The current study found that more than half of the included medical students suffered from severe internet addiction and $43.4 \%$ of them were possible addicts. High prevalence of severe internet addiction may be attributed to easy access to internet as most people nowadays can access to internet through their personal mobiles and also may be attributed to the occurrence of COVID-19 pandemic which increase the need to use internet to continuously check for its news, prevalence and mortality rates and also may be due to lockdown measures and panic states that affect most people and urge them to overuse internet as an escaping mechanism.

These results are in contrary with Taha et al. findings of their study as they found only $12.4 \%$ of medical students were severely addicted to internet while $57.9 \%$ of them were possible addicts (Taha et al. 2019). Moreover, Srijampana et al., in their study in India found that only $0.4 \%$ of medical students were severe addicts to internet and $11.8 \%$ of them were possible addicts (Srijampana et al. 2014).

Furthermore, Haque et al. in their Malaysian study didn't found any of their students was severely addicted to internet and only $32 \%$ of them experienced occasional or frequent problems caused by their Internet use as they were possible addicts (Haque et al. 2016).

On comparing medical and non-medical students, the present study found that the medical students were severe internet addicts (51.7\%) more than the non-medical ones $(11.3 \%)$ with statistically significant difference between them. This is in contrary with Soni et al., findings, as they found that medical students are less than students in faculty of engineering in internet addiction $(2.5 \%$ of medical students and $12.5 \%$ of engineering students were severe internet addicts). However, they found that a similar percent of students in faculty of commerce (2.5\%) and none of students in faculty of art were severe internet addicts (Soni et al. 2020).

Regarding the gender differences in internet addiction, the present study found that female medical students were severely addicted to internet more than males $(71.5 \%$ of the severe internet addicts were females compared to $28.5 \%$ were males), which is consistent with findings of Taha et al. in their study (Taha et al. 2019).

These findings were in contrary to results of study done in Tanzania by Mboya et al., as they found that males were internet addicts more than females (Mboya et al. 2020) and also in contrary with Soni et al. findings from their study in Raipur, India as they found that prevalence of internet addiction among medical students was more among males tan females $(22.5 \%$ of males were moderate internet addicts 
compared to only $7.5 \%$ of females while $2.5 \%$ of males were severe addicts and non of females were severe addicts) (Soni et al. 2020).

Also, our findings were different from Srijampana et al., results as they found that males and females were equally suffered from internet without any difference (Srijampana et al. 2014).

Regarding non-medical students; the present study also found that female students were more addicted to internet than male ones. This is in contrary with Soni et al. results in their study on arts, commerce and engineering students as they found that male students in these 3 colleges were addicted to internet more tan female students (Soni et al. 2020).

\section{Recommendations:}

We recommend developing appropriate preventive, awareness and intervention strategies to stop this excessive use of internet among university students and protect their physical and mental health from its harmful consequences. Students must be encouraged to use other recreational activities to help them to cope more appropriately with stress, panic and isolation caused by such COVID-19 pandemic events.

\section{Conclusions}

The current study observed that, during COVID 19 pandemic, internet addiction was more prevalent among medical students than non-medical students with more than half of the medical students suffered from severe internet addiction, which negatively affected their personal lives, their academic performances and night sleep. Also, our study revealed that female students, either medical or nonmedical, suffered from internet addiction more than male students. These results showed that compulsive use internet reaching to a state of severe addiction among university students was strongly attributed to worries of COVID-19 or as a symptom of depression, isolation, loneliness or even escapism.

\section{Declarations}

\section{Conflict of Interest:}

No conflict of interest was declared by authors.

\section{Funding:}

No fund was received by authors for this work.

\section{Acknowledgement:}

The authors would like to thank all students who participated in our study.

Author contribution: This study formed part of Dr. Walaa M. Shehata who compiled the draft manuscript and Dr. Doaa E. Abdeldaim who analyzed the data. Both contribute in interpretation of the results, and 
write up.

Data availability: not applicable.

Consent to participate: Not applicable.

Consent for publication: Not applicable.

\section{References}

1. Ali RA, Mohammed NA, Aly HY(June 2017). Internet addiction among medical students of Sohag University, Egypt. Journal of the Egyptian public health association 92(2): 86-95.

2. Al-Menayes JJ (2015) Dimensions of social media addiction among university students in Kuwait. Psychol Behav Sci 4:23-28.

3. Babakr ZH, Majeed K, Mohamedamin P, Kakamad K (2019) Internet addiction in Kurdistan university students: prevalence and association with self-control. Eur J Educ Res 8(3):867-873.

4. Bahrainian SA, Alizadeh KH, Raeisoon MR, Gorji OH, Khazaee A (2014) Relationship of internet addiction with self-esteem and depression in university students. J Prev Med Hyg 55(3):86-89.

5. Derbyshire KL, Lust KA, Schreiber LRN, Odlaug BL, Christenson GA, Golden DJ, Grant JE (2013) Problematic internet use and associated risks in a college sample. Compr Psychiatry 54(5):415-422.

6. Fernandes B, Biswas UN, Tan-Mansukhani R, Vallejo A \& Essau CA(2020). The impact of COVID-19 lockdown on internet use and escapism in adolescents. Revista de Psicología Clínica con Niños y Adolescentes 7 (3):59-65

7. Fegert JM, Vitiello B, Plener PL, and Clemens V (2020) Challenges and burden of the Coronavirus 2019 (COVID-19) pandemic for child and adolescent mental health: a narrative review to highlight clinical and research needs in the acute phase and the long return to normality. Child Adolesc Psychiatry Ment Health 14:20.

8. Griffiths M (2000) Does Internet and computer "addiction" exist? Some case study evidence. Cyberpsychol Behav 3:211-218.

9. Haque M, Rahman NA, Majumder MA, Haque SZ, Kamal ZM, Islam Z, et al ( (2016) Internet use and addiction among medical students of Universiti Sultan Zainal Abidin, Malaysia. Psychol Res Behav Manag 9:297-307.

10. Johnson J (2020). Worldwide digital population as of October 2020. Statista; Jan 27, 2021. Available at: https://www.statista.com/statistics/617136/digital-population-worldwide/ accessed at 23.2.2021

11. KEMP S(2020): DIGITAL 2020: EGYPT, Datareportal, 17 FEBRUARY 2020.

https://datareportal.com/reports/digital-2020-egypt\# Accessed at 23.2.2021

12. Király O, Potenza MN, Stein DJ, King DL, Hodgins DC, Saunders JB, Demetrovics Z (2020) Preventing problematic internet use during the COVID-19 pandemic: Consensus guidance. Compr Psychiatry 100:152180. 
13. Krishnamurthy S, Chetlapalli SK (2015). Internet addiction: Prevalence and risk factors: A crosssectional study among college students in Bengaluru, the Silicon Valley of India. Indian J Public Health59:115 - 21

14. Kuss DJ, Lopez-Fernandez O(2016). Internet addiction and problematic Internet use: A systematic review of clinical research. World J Psychiatry 6:143-76

15. Lee S-Y, Kim MS, Lee HK (2019) Prevention strategies and interventions for internet use disorders due to addictive behaviors based on an integrative conceptual model. Curr Addict Rep 6(3):303-312.

16. Maroma FO, Karega M, Oteyo JS (2019) Relationship between depression and pathological internet use among university students. Cypriot J Educ Sci 14(2):201-207.

17. Mboya IB, Leyaro BJ, Kongo A, Mkombe C, Kyando E and George J(2020). Internet addiction and associated factors among medical and allied health sciences students in northern Tanzania: a crosssectional study. BMC Psychology 8:73

18. Merriam-Webster's Dictionary(2019). "addiction". From: https://www. merriamwebster.com/dictionary/addiction Accessed: Jan 2019

19. Mercy ON, Oluwatosin BO(2015). Internet addiction among undergraduates in University of Ibadan: imperative for counselling intervention. Afr J Psychol Stud Soc Issues18(3):1-14

20. Patil SD, Deshmukh JS, Dagdiya KR (2017) Prevalence and pattern of internet addiction among medical students in Nagpur, Maharashtra. Int J Community Med Public Health 4:2412-2416.

21. Saied SM, Elsabagh HM, El-Afandy AM (2016) Internet and Facebook addiction among Egyptian and Malaysian medical students: A comparative study, Tanta University, Egypt. Int J Community Med Public Health 3:1288-1297.

22. Salubi OG, Nekhwevha F, Oyediran-Tidings S, Ondari-Okemwa E (2018) Digital media usage and prevalence of internet addiction among undergraduate students in South Africa. Int J Web Appl 10(4):127-136.

23. Sato T(2006). Internet addiction among students: Prevalence and psychological problems in Japan. Japan Med Assoc J 49:279-83

24. Smita G, Azhar F(2018). Prevalence and characteristics of internet addiction among university students in Mauritius. SM J Case Rep4(1):1077

25. Soni K, Alam MN, Joshi PR, Kaore NM, Singh SP(2020). Comparative evaluation of internet addiction amongst arts, commerce, engineering and medical students. Int J Community Med Public Health 7:3197 - 201

26. Srijampana VVGR, Endreddy AR, Prabhath K, Rajana B (2014) Prevalence and patterns of internet addiction among medical students. Med J Dr DY Patil Univ 7:709-713.

27. Taha MH, Shehzad K, Alamro AS and Wadi M (2019). Internet Use and Addiction Among Medical Students in Qassim University, Saudi Arabia. Sultan Qaboos University Med J, Vol. 19, Iss. 2, pp. e142-147 
28. WHO (2015). Public health implications of excessive use of the internet, computers, smartphones and similar electronic devices: meeting report, Main Meeting Hall, Foundation for Promotion of Cancer Research, National Cancer Research Centre, Tokyo, Japan, 27-29 August 2014. Geneva: World Health Organization; 2015

29. Whang LS, Lee S, Chang G (2003) Internet over-users' psychological profiles: A behavior sampling analysis on Internet addiction. Cyberpsychol Behav 6:143-150.

30. Young K (1998) Internet addiction: the emergence of a new clinical disorder. Cyber Psychol Behav 1(3):237-244.

\section{Tables}

Due to technical limitations, table 1-4 is only available as a download in the Supplemental Files section.

\section{Supplementary Files}

This is a list of supplementary files associated with this preprint. Click to download.

- Table14.pdf 